\section{Letter to the} Editor

\section{Vitamin D Supplementation Should Be Considered for the Treatment of COVID-19 Infection in Malaysia in View of the High Prevalence of Vitamin D Deficiency}

Submitted: 10 May 2021 Accepted: 14 Jun 2021

Online: 22 Dec 2021

\section{Shamin MOHD SAFFIAN}

Centre for Quality Management of Medicines, Faculty of Pharmacy, Universiti Kebangsaan Malaysia, Kuala Lumpur, Malaysia

To cite this article: Mohd Saffian S. Vitamin D supplementation should be considered for the treatment of COVID-19 infection in Malaysia in view of the high prevalence of vitamin D deficiency. Malays J Med Sci. 2021;28(6):194-196. https://doi.org/10.21315/mjms2021.28.6.15

To link to this article: https://doi.org/10.21315/mjms2021.28.6.15

Dear Editor,

The significance of vitamin $\mathrm{D}$ requirements for bone and muscle health is well recognised and has been repeatedly discussed in the literature. However, many readers might not be aware of the role of vitamin $\mathrm{D}$ in the immune system and the growing evidence that vitamin $\mathrm{D}$ plays a crucial role in COVID-19 infection $(1,2)$. This letter briefly describes observational and intervention studies on the relationship between vitamin D and COVID-19 infection and provides some insights into the local situation in Malaysia.

Recently, Pereira et al. (3) conducted a systematic review of 27 observational studies that investigated the relationship between vitamin D deficiency and the severity of COVID-19 infection. The 27 studies were conducted worldwide, including Europe $(n=$ 15), the Mediterranean $(n=2)$, the USA $(n=$ 3), the Western Pacific $(n=3)$, South Asia ( $n$ $=2)$ and Indonesia $(n=2)$. They found that patients with severe COVID-19 had markedly low vitamin $\mathrm{D}$ levels and the fatality rate was high in vitamin D-deficient groups, but vitamin $\mathrm{D}$ deficiency was not associated with a higher risk of COVID-19 infection. It is important to note that the geographical distribution was important because COVID-19 fatalities were found to be highly correlated to latitude, which is linked to vitamin D deficiency (4). While not necessarily causative, because respiratory tract infections can lower vitamin D levels (5), these studies point towards a strong relationship between vitamin D levels and the severity of COVID-19 infection.
Several randomised controlled trials (RCTs) have been conducted to investigate whether vitamin D supplementation can improve clinical outcomes in COVID-19 infections. A group of Spanish researchers treated 50 randomised patients with high doses of calcifediol plus standard care, while 26 others received only standard care. They showed that calcifedioltreated patients with COVID-19 infection required significantly less intensive care unit (ICU) treatment in hospitalised patients (6). A clinical trial conducted in India supplemented 60,000 IU of cholecalciferol in 16 COVID-19 patients, while 20 other patients received a placebo. All the patients in the trial were vitamin D deficient (defined as 25(OH)D level $<20 \mathrm{ng} / \mathrm{mL}$ ). After administering the vitamin D supplementation for a week, the investigators found that it improved various COVID-19 severity markers (7). Also, two French studies $(8,9)$ that used a quasiexperimental study design found that vitamin D supplementation improved survival.

However, not all trials have shown improvement in COVID-19-infected patients with vitamin D supplementation. A Brazilian RCT (10) published in JAMA did not demonstrate the same effect as the other trials mentioned here. However, as detailed by the editor of JAMA (11), several limitations would limit the generalisability of their findings.

One may next ask, how prevalent is vitamin D deficiency in Malaysia? A local longitudinal study called MyHeARTs found that $78.9 \%$ of 1361 sampled 13-year-old Malaysian adolescents 
Letter to the Editor | Vitamin D supplementation and COVID-19 in Malaysia

had vitamin D deficiency $(12,13)$. Another study of 57 pregnant women sampled from the Kuala Lumpur area found that $91 \%$ were vitamin D deficient (14). This was echoed by another larger study, where $42.4 \%$ of 535 pregnant women were found to be vitamin D deficient (15). It has also been shown that urban women in Malaysia had significantly lower vitamin D levels compared to rural women (16), while a slightly dated but still relevant study showed that approximately $68 \%$ of Malay adults in Kuala Lumpur had insufficient vitamin D levels $(n=380)(17)$. Overarchingly, these studies have repeatedly indicated that many Malaysians do not have the recommended level of vitamin $\mathrm{D}$.

It is well known that adequate exposure to sunlight together with a healthy diet is the best way to increase circulating vitamin D levels. However, because of our lifestyles in the new norm, this might not be a feasible option for everyone. Therefore, vitamin D supplementation for individuals who are deficient has been suggested by some authors as a method to increase circulating vitamin $\mathrm{D}$ and consequently improve innate and adaptive immunity (1). However, it should be noted that vitamin D supplementation should only be part of general measures in the fight against COVID-19. It does not, in any way, negate the need for other measures, such as a healthy diet, adequate sleep and physical exercise, avoiding and relieving stress and other proven preventative measures, including physical distancing, hand washing and wearing face masks.

\section{Acknowledgements}

None.

\section{Conflict of Interest}

None.

\section{Funds}

None.

\section{Correspondence}

Dr Shamin Mohd Saffian

BPharm (Otago), PgCertPharm (Otago), PhD

(Otago)

Faculty of Pharmacy,

Universiti Kebangsaan Malaysia, Jalan Raja

Muda Abdul Aziz,

Kuala Lumpur 50300, Malaysia.

Tel: +60392897464

E-mail: shamin@ukm.edu.my

\section{References}

1. Shah Alam M, Czajkowsky DM, Aminul Islam M, Ataur Rahman M. The role of vitamin D in reducing SARS-CoV-2 infection: an update. Int Immunopharmacol. 2021;97:107686. https://doi. org/10.1016/j.intimp.2021.107686

2. Charoenngam N, Shirvani A, Holick MF. Vitamin $\mathrm{D}$ and its potential benefit for the COVID-19 pandemic. Endocr Pract. 2021;27(5):484-493. https://doi.org/10.1016/j.eprac.2021.03.006

3. Pereira M, Dantas Damascena A, Galvão Azevedo LM, de Almeida Oliveira T, da Mota Santana J. Vitamin D deficiency aggravates COVID-19: systematic review and meta-analysis. Crit Rev Food Sci Nutr. 2020:1-9. https://doi.org/10.1080 /10408398.2020.1841090

4. Whittemore PB. COVID-19 fatalities, latitude, sunlight, and vitamin D. Am J Infect Control. 2020;48(9):1042-1044. https://doi. org/10.1016/j.ajic.2020.06.193

5. Smolders J, van den Ouweland J, Geven C, Pickkers P, Kox M. Letter to the editor: Vitamin D deficiency in COVID-19: mixing up cause and consequence. Metabolism. 2021;115:154434. https://doi.org/10.1016/j.metabol.2020.154434

6. Entrenas Castillo M, Entrenas Costa LM, Vaquero Barrios JM, Alcalá Díaz JF, López Miranda J, Bouillon R, et al. Effect of calcifediol treatment and best available therapy versus best available therapy on intensive care unit admission and mortality among patients hospitalized for COVID-19: a pilot randomized clinical study. $J$ Steroid Biochem Mol Biol. 2020;203:105751. https://doi.org/10.1016/j.jsbmb.2020.105751 
7. Rastogi A, Bhansali A, Khare N, Suri V, Yaddanapudi N, Sachdeva N, et al. Short term, high-dose vitamin $\mathrm{D}$ supplementation for COVID-19 disease: a randomised, placebocontrolled, study (SHADE study). Postgrad Med J. 2020:1-4. https://doi.org/10.1136/ postgradmedj-2020-139065

8. Annweiler G, Corvaisier M, Gautier J, Dubée V, Legrand E, Sacco G, et al. Vitamin D supplementation associated to better survival in hospitalized frail elderly COVID-19 patients: the GERIA-COVID quasi-experimental study. Nutrients. 2020;12(11):3377. https://doi. org/10.339o/nu12113377

9. Annweiler C, Hanotte B, Grandin de l'Eprevier C, Sabatier JM, Lafaie L, Célarier T. Vitamin $\mathrm{D}$ and survival in COVID-19 patients: a quasiexperimental study. J Steroid Biochem Mol Biol. 2020;204:105771. https://doi.org/10.1016/j. jsbmb.2020.105771

10. Murai IH, Fernandes AL, Sales LP, Pinto AJ, Goessler KF, Duran CSC, et al. Effect of a single high dose of vitamin D3 on hospital length of stay in patients with moderate to severe COVID-19: a randomized clinical trial. JAMA. 2021;325(11):1053-106o. https://doi. org/10.1001/jama.2020.26848

11. Leaf DE, Ginde AA. Vitamin $\mathrm{D}_{3}$ to treat COVID-19: different disease, same answer. JAMA. 2021;325(11):1047-1048. https://doi. org/10.1001/jama.2020.26850

12. Al-Sadat N, Majid HA, Sim PY, Su TT, Dahlui $\mathrm{M}$, Abu Bakar MF, et al. Vitamin D deficiency in Malaysian adolescents aged 13 years: findings from the Malaysian Health and Adolescents Longitudinal Research Team study (MyHeARTs). BMJ Open. 2016;6(8):e010689. https://doi. org/10.1136/bmjopen-2015-010689
13. Quah SW, Abdul Majid H, Al-Sadat N, Yahya A, Su TT, Jalaludin MY. Risk factors of vitamin D deficiency among 15-year-old adolescents participating in the Malaysian Health and Adolescents Longitudinal Research Team Study (MyHeARTs). PLoS ONE. 2018;13(7):e0200736. https://doi.org/10.1371/journal.pone.0200736

14. Ariffin MASM, Fazil FN, Yassin NM, Junaida NS, Gan PV, Rahman RA, et al. Prevalence of vitamin $\mathrm{D}$ deficiency and its associated risk factors during early pregnancy in a tropical country: a pilot study. J Clin Diagn Res. 2018;12(9):QC18-QC22. https://doi. org/10.7860/JCDR/2018/36585.12104

15. Woon FC, Chin YS, Ismail IH, Batterham M, Abdul Latiff AH, Gan WY, et al. Vitamin D deficiency during pregnancy and its associated factors among third trimester Malaysian pregnant women. PLOS ONE. 2019;14(6):e0216439. https://doi.org/10.1371/journal.pone.0216439

16. Nurbazlin M, Chee WS, Rokiah P, Tan AT, Chew YY, Nusaibah AR, et al. Effects of sun exposure on $25(\mathrm{OH})$ vitamin $\mathrm{D}$ concentration in urban and rural women in Malaysia. Asia Pac $J$ Clin Nutr. 2013;22(3):391-399.

17. Moy F-M, Bulgiba A. High prevalence of vitamin D insufficiency and its association with obesity and metabolic syndrome among Malay adults in Kuala Lumpur, Malaysia. BMC Public Health. 2011;11(1):735. https://doi.org/10.1186/14712458-11-735 